\title{
The logic of agency or the logic of structure in the concept of white collar crime: a review
}

\author{
Tage Alalehto ${ }^{1}$ \\ Published online: 18 November 2017 \\ (C) The Author(s) 2017. This article is an open access publication
}

\begin{abstract}
Since 60s the white collar crime concept is divided in occupational crime versus corporate crime, exposing two different causal primacy: an agency logic and a structural logic. The logic of agency argues that corporate crime concept and the logic of structure is more or less useless for white collar crime research. The logic of structure argues that corporate crime has a validity in its own and describe a dimension of white collar criminality that the logic of agency doesn't reach. The validity of this two positions is discussed by four crucial issues: The status of juristic persona, explanatory value, mens rea and suffering by punishment. It ends up in a Soritie paradox to which a three valued formal logic by the Stoicists Chrysippus is applied. The conclusion is that the logic of agency has the primacy, and the concept of occupational crime should be the prime concept for white collar crime.
\end{abstract}

This essay is a critical review of the two-part division of the concept of white collar crime (WCC) into the subcategories of occupational crime (OC) and corporate crime (CC) that has been the norm in the field of criminology since the 1960s. OC is taken to mean crime committed by self-interested individuals in their occupation against clients, customers, etc. and as employees against their employers, while CC is understood as crime committed by corporate officials in the larger interests of a corporation and as those offenses committed by the corporation itself against other organizations ([1]:188). Traditionally then, the two different causal primacies of agency logic and structural logic have been seen as underlying WCC [2]. Both OC and CC have been seen as legitimate subjects of research because they have been identified in several nations' jurisdictions with more or less specified sections of law. ${ }^{1}$ But from a criminological point of view this division of the WCC concept has been seriously questioned for both

\footnotetext{
${ }^{1}$ It applies to a number of countries such as the USA, The Netherlands, France, Britain, Japan, but not to all western European countries, e.g. Germany, Sweden, etc. [3].
}

Tage Alalehto

Tage.Alalehto@umu.se

1 Department of Sociology, Umeå University, Umeå, Sweden 
empirical and theoretical reasons. Firstly, the empirical: How can it be empirically proven that a corporation (a juristic person) acts by force of will, with intentions and motives like that of a natural person? And secondly, the theoretical: How far can two fundamentally different kinds of offenders (the natural and the juristic persons) committing the same type of crime be understood and explained by a general criminological theory? [4].

In the first section of the paper the theoretical background to the question of whether or not a corporate 'will' exists is presented by outlining the principal criticisms made by Donald Cressey and Braithwaite and Fisse's response. In section two, a review of the strengths and weaknesses of the CC concept put forward by various commentators is undertaken through detailed consideration of four crucial issues: The existence or otherwise of an independent juristic persona; the robustness of the $\mathrm{CC}$ concept in terms of explanation and causation; the issue of criminal liability as it affects $\mathrm{CC}$; and the notion of suffering by punishment in relation to $\mathrm{CC}$. I draw the conclusion that the concept of CC is very hard to prove empirically, and without reducing it to the act of an individual's will. I contend that three of the four issues noted above are especially susceptible to criticism, but concede that the issue of explanation and causation does seem to add some theoretical validity to the CC concept. In section three of the paper, therefore, I use a three-valued formal logic (true, false, uncertain) to specifically test if the concept of $\mathrm{CC}$ in relation to the concept of $\mathrm{OC}$ possesses any theoretical validity. My conclusion is that it has not, and thus should be dismissed as a subcategory from the concept of WCC. Finally, I argue that the concept of OC is in itself sufficient to explain what the concept of CC has been previously used to elucidate.

\section{The theoretical background: Criticisms and defense of the existence of a corporate 'will'}

Donald Cressey [4] claimed that $\mathrm{CC}$ research suffered from a theoretical poverty. Everyone, he argued, can understand that a natural person acts by will, intention and motive, and because of this is responsible for his/her acts in the present and future. Every natural person has an ethical duty, according to the social contract principle, to subordinate his personal interests to society, and a legal obligation to behave responsibly to fellow citizens. But, Cressey asserts, a corporation cannot possibly fulfill this contract because it is a fictitious person. It cannot 'feel', it has no conscience, is impervious to shame and guilt, and cannot suffer punishment: To paraphrase Thurlow, a corporation has no soul to damn nor body to kick.

Put simply, a corporation does not think or act by itself because it lacks ethical, philosophical, sociological and psychological properties. Corporate crime is therefore hard to understand and explain in the framework of a criminological theory based solely on social-psychological properties. These properties validate the empirical base that is usually used to explain why a crime occurs in the first place by seeking intention and motive on the part of the perpetrator, and how it can be regulated by a suitable punishment so that the offender feels a sufficient degree of suffering that is commensurate with the magnitude of the crime. Logically, therefore, in Cressey's view the division of the concept of WCC into OC and CC immediately breaks down, and it 
follows that a single causal explanation stemming from a general and unified theory of criminology is not possible.

Cressey's arguments are based purely on the assumptions of methodological individualism, assumptions that were questioned by Braithwaite and Fisse [5] in their response to his work. They claimed that a corporation does, in fact, have most of the properties of an individual, citing the characteristics of acting by itself, possessing intentions, having legal and ethical responsibilities and being cognizant of punishment. A corporation, they argue, is not simply an aggregate of individuals, or an aggregate of individual decisions. It is a force by itself which is superior to the individual. To understand this view fully, we have to understand it from the point of methodological holism.

A corporation has a body, contending assets, factories and plant, decision-making procedures, etc. This body is also an institutional framework in which it makes sense for every worker to behave as a member of the corporation. Take, for example, an accountant at a corporation who behaves as an accountant because there are accounts to deal with, a board to monitor, other accountants to discuss things with and an accounting policy to follow. Take away all of these contextual properties and there is no sense in behaving as an individual accountant.

Behaving as an accountant has nothing to do with personal qualities, the possession of unique competences, kinship patterns or social networking. It is, in fact, a matter of functionality that relies on trusting relationships with other members of the corporation and the nature of the corporate environment itself.

The shared expectations of functionality both inside and outside the corporation constitute the culture of the corporation that is transmitted from one generation of members to the next. It becomes something superior to each individual member of the corporation, and in fact constitutes 'group-think' - a shared way to see and take decisions irrespective of the individual's expectations.

This culture of 'group-think' indicates the corporation's intentions, i.e. the corporate policy stemming from a system of decision-making from the top to the bottom that is defined by specific procedural rules. This policy does not merely express a couple of individuals' motives, but rather expresses the whole corporation's strategy which is defined as its intentions. Thus, the strategy is the basis for the corporation's ethical responsibility for any wrongdoing, and, logically, its blameworthiness in the event of things going wrong. However, according to Braithwaite and Fisse corporate ethical responsibility rests more on corporate negligence than criminal intention. Essentially, corporate negligence stems from a situation where procedural rules are inadequate to prevent a member committing a criminal act, and may even be inadvertently structured to encourage such actions; in these circumstances, the corporation is itself responsible for the crime that has been committed.

So even if a corporation lacks emotions and feelings, it can still commit crime by recklessness, negligence and willful blindness, and because of its ethical responsibility the corporation has - as with a natural person - a moral responsibility for its acts. And as a morally responsible actor, the corporation can suffer from punishment, for example by incurring negative publicity, when wider society damages the collective interests of the corporation by lowering its reputation without affecting the personal interests of the members. 
According to Braithwaite and Fisse, the concerns that Cressey has about the validity of the two-part division of the concept of WCC are unwarranted. Their view is that the individual and the corporation are not so dissimilar after all.

\section{Later critical reflections on the possible existence of a corporate 'will'}

\section{The independent juristic persona}

In the discussion following the Cressey-Braithwaite-Fisse exchange, a central issue concerned the status of the juristic persona: Quite simply, is a corporation a homogenous person (a metaphysical or a sociological entity) showing evidence of a will? According to Bucy [6] and Jörg [7] the answer is 'yes'. Bucy argues that a corporation may develop a distinct identity or 'ethos', which encourages its members to commit crime independently of their own will. The 'ethos' is a result of the dynamic between members when they work together in furtherance of the goals/policies of the corporation, creating thereby a corporate identity entirely separate from the member's individual identity. A similar view was presented by Jörg, who suggested that a corporation of a certain size develops a culture sui generis which produces its own moral competence, i.e. it discriminates between right and wrong. This moral competence stems from the corporation's internal decision-making structure (CID) which comprises not only the forums in which those decisions are made but also the will, the knowledge and freedom to act as an employee within any of the corporation's sub-units.

Jörg's view is typical of the arguments presented by the defenders of the CC concept. It is their position in the organization (as financial administrators, internal auditors, IT workers, etc.) that determines what single members are expected to do, and what kind of relationships they are expected to have with members in other positions.

It is not up to the members to independently decide what they should do and what kind of relationships they want: Basically, their position within the CID dictates how the members fulfill their duties [8, 9].

Related to this idea is the doctrine of identification. If a number of members commit a crime on behalf of the corporation, the 'directed mind' of the members and the criminal act itself is identified as working for the corporation's purposes. In other words, the members and the corporation can be treated as both criminally liable [10, 11].

But a counter-argument to this is put forward by the OC defenders: If we implement a more rigorous empirical investigation of the different contributions from every member of the corporation, we can with more certainty say what the corporation stands for in terms of its policy and thereby delineate its 'mind' more clearly [12]. The policy may well be interpreted as an aggregated behavior, but it basically depends on the will of the single members (all natural persons, of course) acting criminally in the name of the corporation [13]. Take a cartel as an example. It is obvious that a cartel's actus reus (the prohibited act) cannot take place in any other form than as a collective activity undertaken by the members, although some of the individual acts may be perfectly legal in themselves and indeed necessary for the cartel's existence. But this collective trait of actus reus does not account for the cartel's mens rea (wrongful state of mind) which instead is located in the awareness and willingness 
of the members' participation in the cartel [14]. The existence of the juristic person's autonomous self must thereby be disqualified, and the status of juristic person be limited to actus reus and not to mens rea.

\section{Explanation and causation}

A second central issue in the debates stimulated by Cressey, Braithwaite and Fisse is the concept of what is actually meant by an 'explanation' and 'causation' with regard to CC. Take, for example, a man working for a petrochemical corporation in a dangerous environment who slips into an acid pool and drowns in the most horrible manner. The corporation is a juristic person with a duty to monitor what happens at its pool, and so technically this tragic death could be a criminal case. But is this event a consequence of the corporation's strategy/moral competence/'ethos', and its intention in setting the procedural rules that were diligently followed by the worker who drowned, as argued by Braithwaite, Fisse and Jörg? Have the procedural rules really 'produced' the risk of drowning, or just 'resulted' in the risk of drowning? [15]. Or is the whole issue an example of an explanation that is too far-fetched, resting on concepts that are much too imprecise? (e.g. see [16]).

This level of theoretical imprecision is important because what, after all, is the purpose of a theory other than to state that if certain conditions exist (where all other conditions remain equal) then a specific result should ensue? $[12,17]$. In a CC-driven explanation the status of the juristic person in terms of 'functional perpetration' Jörg, [7:107], 'amoral calculator' [18] or 'ethos' [6] is unclear because the empirical concepts are flawed. Because these concepts are connoted to the anthropomorphization of a homogenous will, our observations will be subject to bias, and this will result in confusion and reduce the accuracy of our predictions.

A related question concerning the explanatory power of the $\mathrm{CC}$ concept is the requirement Cressey [4] raises that a criminological theory should be socialpsychological in its nature if its utility is to be admitted (see also [19]). On this question, the defenders of the $\mathrm{CC}$ concept have a significant point: A criminological theory cannot ignore the structural conditions, such as the corporation's policy and strategy, when seeking to explain how the individual's decision-taking process is 'produced'.

However, respond the OC defenders, there will certainly be an empirical variation in how this impact 'produced' by strategy and policy 'results' in each member's decisiontaking which depends on the properties of the individual, not on the properties of the organization [12]. But even with regard to this argument, the defenders of the CC concept have an effective counter point because the variation in the individual's decision-taking is still an effect of the structural arrangements in place around the decision-taking. A corporation is not an anthropomorphized entity driven by a homogenous rationality, but is, in fact, an irrational entity, a multidimensional complex of competing interests and actions made by numerous individuals which at the end has its own superior outcome. It is a product of human agency [20] in that each decision is made by an individual human being. Those decisions can be rational in terms of the situation in which they were made; however, when a decision is raised to a principal level it is interpreted and implemented through an imperfect communication structure (giving incomplete information about its meaning); the goal for the corporation (which is constituted of diverse competing sub-unitary goals) becomes unclear [2, 21] and 
structured by relations of power and segmented moral experiences [22]. Ultimately, this can create a crime-facilitative culture which provides enticing opportunities for those inclined to take advantage [23-25].

There is a huge amount of literature that emphasizes the importance of the structural setting in influencing an individual's decision-taking (e.g. [26-28]), and we may immediately conclude from this that the demand that a criminological theory should be social-psychological in its nature is much too narrow. It is clear that powerful constraints determine work-related actions by the members of large organizations. There are, for example, extensive 'horizontal' levels of divisionalized structures with barriers between them, where one member or unit is responsible for one part of the corporation's production, and another member or unit is responsible for another part of the corporation's productions, and so on with the pattern endlessly replicated. The result is that no one member is responsible for all parts of production in all its complex details because of limited knowledge and the taken-for-granted aspects of the cognition of each actor who is involved [29, 30]. The 'vertical' dimension, where the hierarchical levels are decoupled from each other and the leadership is disconnected from what actually takes place at the operative levels, also exerts a constraining influence. Such decoupling frees the leadership from responsibility by pushing the issue down to operating officials at sub-levels, who in their turn claim that they have limited responsibility, or, indeed, may be victims when things go wrong [20].

This complex combination of formal and informal structures at varying horizontal and vertical levels can promote adverse collective outcomes [6]; members can be subject to constraining influences and do the right thing in their own areas, and yet a collective misdemeanor can still result [31]. This seems counter-intuitive, but a general mechanism for an inadvertent outcome can be illustrated by the idea of 'escalating commitment' [21] in an auction. Individuals calculate beforehand what they can spend, but as soon as the auction starts they begin to bid over their original self-imposed limits (ibid: 63). The process acquires its own life, sometimes with an outcome far beyond and far worse - than what the individuals were originally prepared for [32, 33]. At the level of the individual in a corporation we find that members come and go, microcultures of in- and out-group selection develop, a lack of trust between the employee and employer may arise, severe time pressures to get results and other factors can all create conditions that are ripe to produce 'escalating commitment' and inadvertent outcomes [34]. And on an organizational level, conflicts may arise between efficiency and the need for external legitimacy in institutionalized environments: For example, the demand for quick and easy profit may clash with the implementation of costly environmental measures [20]. In summary, this view of a corporation does not anthropomorphize or give the corporation an autonomous 'will': Rather, it shows that a corporation is a platform of ongoing jostling positions and relations of power. It is, in sum, a powerful institutional framework that must impact upon the single member's actions.

\section{Criminal liability}

A third issue is the relevance of criminal liability (mens rea) to CC. As early as 1957 Gerhard Mueller had stated that corporate criminal liability had no valid theoretical basis: "the rationale of corporate criminal liability...has proceeded without rationale 
whatsoever... It simply rests on an assumption that such liability is a necessary and useful thing. Where the courts try to rationalize, especially with respect to mens rea offenses" (ibid: 22).

It can be seen that Mueller gave little credence to the notion of corporate criminal liability, mostly because of the absence of empirical evidence regarding its utility ([35]: 88). Gilbert Geis [12], in contrast, interpreted this issue as essentially about intentionality, taking his lead from Braithwaite and Fisse who argued that a corporate strategy may be defined as the intention of the corporation. But what does that mean? If we can actually specify the strategy and prove that it contains an element of willful ignorance despite the objections of single members ([12]: 465), can we begin to speak of something like the superior will of criminal intentionality on the part of a corporation? To return to the example of the drowned worker at the petrochemical corporation: Can it be specified empirically that this tragic death was a consequence of willful ignorance inscribed in the procedural rules of the corporate strategy, which sidestepped the knowledge of every single member (including the CEO) of what would happen if the worker strictly followed the regulations when monitoring the acid pools?

Looked at from the point of view of the defenders of OC, the answer is a plain and simple 'no'. Criminal liability demands a conscious and guilty mind, and since a corporation does not have a mind it cannot feel guilty and therefore cannot be criminally responsible [36]. The fate of the drowned worker is therefore just an unfortunate accident; it has nothing to do with criminality whatsoever. This is a view that aggregated non-anthropomorphic defenders of the $\mathrm{CC}$ concept also can agree with. It is, after all, impossible to give any proof of the existence of a mind and a direct intention by the corporation. And even if we could confirm the independent existence of a corporation that was acting by itself, and even if its actions were classified as wrong, its wrongdoing would still not be intentional; such an outcome would be the result of limited individual actions. Therefore it is inappropriate to demand that corporations should be held criminally responsible, and thereby proved of mens rea [11, 31].

In light of the above, we may safely conclude that direct intention by a corporate mind is impossible to prove, but is it possible to prove indirect intention? [6]. If so, it should exist among the functionaries of the corporation who have lost their sense of self-determination and simply follow orders. The corporation's guilty mind should be diffused among these functionaries [3].

This hypothesis has so far not been proven, and indeed it is hard to accept that it could ever be proved empirically. But this conceptual problem may be overcome if we simply just accept, sui generis, a corporate mind exhibiting a superior will, knowledge and freedom to act entirely independent of its constituent members Jörg, [7]. This rather grandiose metaphysical assumption raises objections about penal status because it treats the corporation as a natural person without proving that its properties really exist (e.g. [37]). And, of course, there are objections from a methodological point of view, as it is difficult to formulate testable propositions derived from such a theory ([17]: 160).

The defenders of the CC concept also point to the doctrine of vicarious liability. Every corporation performs its acts through the activities of its agents, which means that a corporation is responsible for all the acts an employee does because they are intended to benefit the corporation [7,38]. This is obviously a juridical and technical 
description, and one that is often made in American courts by lawyers seeking to determine the corporation's responsibility [9]. The legal purpose of these arguments is to make the corporation liable for what its employees do, but it leaves aside the issue of the explanatory purpose in determining whether the corporation acts by itself through a conscious and reasoning mind [15]. Instead, the doctrine of vicarious liability concentrates on whether the members carry out their act of crime on behalf of the corporation or on behalf of their own interests. Which followed to the logical conclusion means, of course, that the corporation's mind is actually an aggregate of individual actions taken by single members [31].

\section{Punishment and suffering}

The fourth issue to be considered is if a corporation can suffer punishment and endure suffering. Fisse and Braithwaite [39] assert that negative publicity has a significant effect which hurts the corporation's reputation with a resulting decline in stock values. Other researchers are not quite so sure about this. Simpson et al. [40] cautiously suggest in their review that negative publicity may affect a corporation's actions through some unspecified inhibitory effect. But Alalehto [41] is much more clear: He shows that the decline in stock values caused by negative publicity may be limited to a period of just four days. In the cases that he examined, a mere two weeks later the stock values were back to their ordinary levels. And this is not surprising because large corporations (based on total sale annually) are significant more involved in criminal activity than small and medium large corporations [29, 42]. Thus, negative publicity as a form of sanction is by no means an unconditional proof that corporations can suffer punishment.

When it comes to monetary punishment (which might be thought to carry more practical weight), the assumption made by Coffee [43] that different kinds of fines can have a deterrent effect is not confirmed. In fact, there are a number of investigations showing that fines are nowhere near enough to moderate corporate behavior; in the end fines imposed on a corporation are mostly passed on to the stockholders, creditors, workforce and consumers in various forms [21].

When it comes to the impact of general deterrence, Craig Smith et al. [44] show that managers' decision-making when acting on behalf of the corporation was directly affected by the control of their social network (within and outside the workplace) and to a much lesser degree by legal formal control. At best, analysis on an organizational level could find only weak supporting proof that corporations were affected by detection of serious wrongdoing or sanctions imposed by society [45].

\section{What do we know and what are we not sure about?}

Empirical investigations concerning the status of an independent juristic person, the possibility of mens rea and the possibility of a corporation suffering punishment, have produced at best only limited support for the CC concept. The models that demonstrate how a corporation could theoretically have a 'will' of its own, possess a mind potentially conscious of guilt and be capable of suffering punishment are fascinating in themselves, but the empirical proof for the models are very weak. Thus, more or less 
every issue considered so far supports Cressey's argument, and the position of methodological individualism.

But the issue of explanation and causation to some extent endorses the logic of structure and the CC concept: The logic of agency is just too narrow to explain complex criminality in large organizations involving non-communicating members/units operating at a horizontal level and/or in the form of decoupled agents at vertical levels.

The concept of $\mathrm{CC}$ can be seen as legitimate if we look at a crime taking place in a large organization, carried out by mutually unconnected agents with no apparent criminal intent or motivation. That is, when actions are constituted by procedural rules, fixed power relations, divisionalized structures with barriers and taken-for-granted cognition, etc., but the outcome of the actions by all involved (unconnected and noncriminally motivated agents) still ends up in criminality. To understand this rather abstract situation, we have to see the organization as a structure of different social positions affecting the members' relations toward each other, but not the other way around: The members and their relationships do not affect the organization [8]. The larger the size of the units and the more members and social positions, the more the explanation of crime should lie in the logic of structure, and vice versa - the smaller the units and the fewer members and social positions, the more the explanation of crime should lie in the logic of individual agency.

But having said this, the distinction between the logic of agency and the logic of structure is not empirical, it is analytical. Even if we can conclude that the organization is not a creation of the actual members' activity, and that the structural properties of the organization endure beyond the lifetimes of the members, it does not mean that the organization's continuity exists beyond the reproduction that the members undertake in the organization. There is always a situational moment of 'subjectivity' (acting through cultural meaning) and 'objectivity' (overall economic, political, technological parameters) in the life of an organization [46].

Somewhere in the complexity of a large organization, the number of members in disparate units reaches the threshold where the logic of agency as a reasonable explanation (at least in the main) for the crime fails and the logic of structure must take over. But where is this critical point?

We may, at this juncture, offer an illuminating example from an unexpected source. Compare the critical threshold just mentioned with the negotiation between God and Abraham in Genesis (18: 23-33), when God considers whether or not to wipe out the city of Sodom. As a servant, Abraham does not question God's intention directly, but he asks God to consider if the destruction might be unfair if there were fifty righteous people living in Sodom who were to be wiped out with the rest of the unrighteous population. Persuaded by the force of this argument, God decides to preserve Sodom for the sake of the fifty righteous people. But in that case, suggests Abraham, does it really matter if it has to be exactly fifty people? Would not forty-five good people be enough to preserve Sodom: Surely the issue cannot depend on just five persons? So God accepts forty-five as the limit. But if forty-five is good enough why cannot forty be good enough, presses Abraham. And once again God accepts this as the number of righteous people necessary to preserve Sodom. The negotiation goes on all the way down to ten righteous people before Abraham wisely decides not to push God any further on the number of persons required to save the wicked inhabitants of Sodom. 
The negotiation between God and Abraham is an example of the philosophical Sorites paradox. This paradox concerns definitional distinction in concepts, and can be invoked as a criticism of the logic of induction ${ }^{2}$ [47]. The paradox depends on the vagueness of the concept, following the propositional logic of moving the reference point upward or downward in relation to the concept [48]. We may apply the Sorites paradox to the border between the $\mathrm{CC}$ and $\mathrm{OC}$ concepts, by a principal example: We have a company with one employer and four employees, where the employer is completely responsible for ensuring that the company follows rules and regulations. The employer decides to recruit one more employee. Does this recruitment create a superior organizational structure superseding the employer's responsibility for ensuring that the company adheres to regulations and laws? If that additional employee does not matter in this respect, does it then matter if one more employee is recruited? And thereafter if periodically $(n+1)$ a further employee is recruited endlessly? If all these endless premises are true, then the conclusion must be that the employer is always completely responsible for running the company.

But such a conclusion cannot be empirically true because for every new employee recruited there must be some differences when it comes to the responsibility for how the company adheres to regulations and laws and discharges its legal obligations. Thus, we should reach a level when the company has grown to a corporation of divisionalized units fulfilling its activities with regard to regulations and laws. Therefore it seems reasonable to think that the process of increasing in size and complexity causes a superior quality in the organization to emerge which affects the corporation's fulfilling its legal obligations over and above any decisions made by the single employee. In fact, the single employee's decision can, in this later scenario, be seen as a result of the corporation's superior properties, and not as a product of the employee's own intentions.

But can we decide exactly where this threshold of accumulated quantity turns into a new quality of responsibility, and is there any external validity for the $\mathrm{CC}$ concept in its positional relation to the OC concept? On an empirical basis there is not, because every principle cut-off point for a threshold for a concept is arbitrary and dependent on context [49].

Instead of looking for external validity, a more fruitful way of exploring the distinction between the concepts of CC and OC is by using the logic of the Stoicists, specifically the philosopher Chrysippus [47, 49]. Put simply, we take the point of departure in our cognitive impression from what we know is 'true', 'false' or 'uncertain' based on what we have so far observed or what we know with certainty.

Looking back at the first of the four issues considered above we can say that the existence of a natural person is true, and that the existence of a juristic person is uncertain:

(1) It is true that the natural person exists and has a mind and a will and can therefore commit an occupational crime. ${ }^{3}$

\footnotetext{
${ }^{2}$ E.g. how many observations constitute an experience, and specifically a valid experience?

${ }^{3}$ Let 'natural person exists' be $\mathrm{x}$ and 'has a mind and a will' be $\mathrm{y}$ and 'occupational crime' be $\mathrm{z}$. Then we will have: $(x \& y) \rightarrow z$. Read: If a natural person exists and has a mind and a will, then we will have occupational crime.
} 
(2) The existence of the juristic person is uncertain, ${ }^{4}$ and thus we cannot say with certainty that it has a mind and a will and can, therefore, commit a corporate crime. ${ }^{5}$

(3) If the existence of a juristic person possessing a mind and will is neither true nor false, then it must be true that the existence of a juristic person having a mind and will is neither true nor false. ${ }^{6}$

If it were true or false that the juristic person exists and has a mind and a will (or, being non-existent, having no mind and no will), then the status of corporate crime would be clear. But that is not the case here: It is uncertain because it is neither true nor false that the juristic person exists and has a mind and a will, which is a tautological true proposition (3). This is in contrast to OC which is true because a natural person exists and has a mind and a will and therefore the capacity to commit an occupational crime (1).

The same logical strategy can be applied to the issue of mens rea:

(4) It is true that an individual actor has a mind capable of feeling a sense of guilt and can be criminally liable for an occupational crime.

(5) It is uncertain whether a superior/aggregated actor has a mind capable of feeling a sense of guilt and can be criminally liable for a corporate crime.

(6) It is uncertain if an individual actor can be criminally liable for a corporate crime even though it has a mind capable of feeling guilt.

(7) It is false to say that a superior/aggregated actor has a mind capable of feeling a sense of guilt and can be criminally liable for an occupational crime. ${ }^{7}$

And the issue of suffering punishment:

(8) It is true that an individual actor can feel shame and suffer for an occupational crime.

(9) It is uncertain whether a superior/aggregated actor can feel shame and suffer for a corporate crime.

(10) It is uncertain if an individual actor can feel shame and suffer for a corporate crime.

(11) It is false to say that a superior/aggregated actor can feel shame and suffer for an occupational crime.

The final issue of the four we have considered - that concerning causation and explanation - also goes in the same direction. We know that:

(12) It is true that the individual actor's properties cause and can explain occupational crime.

\footnotetext{
${ }^{4}$ It is uncertain if it exists as a physical thing, like a natural person.

${ }^{5}$ Which is, of course, a tautology. Let 'juristic person exists' be $\mathrm{x}$ and 'has a mind and a will' be $\mathrm{y}$ and 'corporate crime' be $\mathrm{z}$. Then we will have: $((\mathrm{x} V-\mathrm{x}) \&(\mathrm{y} V-\mathrm{y})) \rightarrow(\mathrm{z} V-\mathrm{z})$. Read: If a juristic person exists or does not exist and has a mind and a will or has no mind and no will, then we will have corporate crime or no corporate crime.

${ }^{6}$ Which is also a tautology: $(x \mathrm{Vy}) \rightarrow((\mathrm{x} V \mathrm{y}) \mathrm{V}(-\mathrm{x} \mathrm{V}-\mathrm{y}))$. Read: If the juristic person is true or false, then the juristic person is true or false or the juristic person is non-true or non-false.

${ }^{7}$ It is false because of the given definition. Or formalized: - $(x \& y) \rightarrow z$. Read: If the aggregated actor has a non-guilty mind and non-criminal liability, then it must be an occupational crime.
} 
(13) It is true that the superior/aggregated actor's properties cause and can explain corporate crime.

(14) It is uncertain whether the individual actor's properties are sufficient to cause and explain corporate crime.

(15) It is false that the superior/aggregated actor's properties cause and can explain occupational crime.

Based on what we know from formal definitions and our observations, the propositions (12), (13) and (15) are unambiguous. It is, however, uncertain if (14) can partially, but not fully, cause and explain corporate crime. Some properties of corporate crime are, it seems, not identical with the properties of an individual actor; instead these properties seem to be connoted only to the properties of a superior/aggregated actor.

So it is true that an individual actor can be criminally liable, has a mind capable of feeling a sense of guilt, feels shame and can suffer. Thus the individual actor can cause and explain an occupational crime (tautology). It is also true that it is uncertain (e.g. (3)) if exactly the same properties of the individual actor apply to a corporate crime. It is true that a superior/aggregated actor can cause and explain a corporate crime (tautology). But it is false that a superior/aggregated actor has a mind that can understand and feel guilt, be criminally liable, feel shame and suffer over an occupational crime. And it is also true that it is uncertain (e.g. (3)) if the same properties of a superior/aggregated actor applies to a corporate crime.

If we apply the principle of the excluded middle, we can state that propositions (1), (4), (8) and (12) are true, although (12) is a tautology. An individual actor exists as a natural person with a mind and a will. It has a mind that can sense guilt, it can be criminally liable, feels shame and can suffer punishment for an occupational crime. And thus it can cause and explain occupational crime. It is true that a superior/ aggregated actor can cause and explain corporate crime (13), which is a tautology, but on the other hand (7), (11) and (15) are false: A superior/aggregated actor does not have a mind that can feel guilt, be criminally liable, feel shame and suffer punishment for an occupational crime. And it cannot cause and explain occupational crime. Every other proposition is a tautological truth in its uncertainty in that they are either true or false and can therefore be excluded (along with the two tautological propositions) from the schedule.

If this analytical schedule is logically consistent then, following the principle of Ochhams razor, the status of OC should be preserved as a subcategory within the concept of WCC, while the status of CC should be dismissed. There are at least three true propositions which deal with the concept of OC, and three false propositions concerning the concept of CC. Every other proposition is uncertain, meaning, according to what we know today, that they are either true or false.

As things stand today, OC is viewed as a subcategory of WCC. However, and on the basis of what we unequivocally know is true and false, and what we are truly uncertain of (mainly the status of CC), OC should instead be seen as identical to the concept of WCC.

This radical conclusion does not, however, mean that the familiar aspects of divisionalization, horizontal and vertical labor, structural power relations and so forth have to be excluded from the WCC research agenda. The definition of OC says only that the crime is committed by individuals: Since individuals are embedded in 
divisionalized organizations, and crimes take place within such organizational bases they must be committed by individuals. Yet this does not require, as Cressey claims, that criminological theory must be exclusively social-psychological in nature. Because if we let 'organization' be $\mathrm{x}$, 'carrying' be $\mathrm{y}$, 'relations between themselves' be $\mathrm{z}$, 'individuals existing' be E, 'divisionalized org.' be D, 'horizontal/vertical org.' be H, 'structured power relations' be $\mathrm{P}$ and 'social psychological properties' be S. Then we will have:

$$
\forall x(O x \& D x \text { V Hx V Px } \rightarrow E x y z \& S x)
$$

It applies for all $\mathrm{x}$, if $\mathrm{x}$ is organization and $\mathrm{x}$ is divisionalized or horizontal/vertical or structured power relations, then $\mathrm{x}$ consists of existing individuals who carry relations between themselves with social psychological properties.

This formula is still valid even if we change the end of it to:

$$
\forall x(\text { Ox\&Dx V Hx V Px } \rightarrow \text { Exyz\&-Sx })
$$

so that it becomes a sufficiently reasonable condition that we have criminal activity in organizations even if there are no social-psychological properties.

But if we change the formula to

$$
\forall x(\text { Ox\&Dx V Hx V Px } \rightarrow \text { Sxyz\&-Ex })
$$

it will be unreasonable to claim the existence of ongoing criminality in organizations resting on just social-psychological properties without existing individuals.

A comprehensive criminological theory may well be based on many and varied components, but it must include that individual's commit acts of crime (actus reus) connected to mens rea.

Open Access This article is distributed under the terms of the Creative Commons Attribution 4.0 International License (http://creativecommons.org/licenses/by/4.0/), which permits unrestricted use, distribution, and reproduction in any medium, provided you give appropriate credit to the original author(s) and the source, provide a link to the Creative Commons license, and indicate if changes were made.

\section{References}

1. Clinard, M. B., \& Quinney, R. (1973). Corporate criminal behavior. In Criminal behavior systems: a typology. New York: Holt, Rinehard \& Winston.

2. Lofquist, W. S. (1997). A framework for analysis of the theories and issues in corporate crime. In Debating corporate crime (pp. 1-29). Cincinnati: ACJS/Andersson.

3. Hatashin, O. (2008). Crime and Culture. In Corporate and White Collar Crime (pp. 141).

4. Cressey, D. R. (1989). The poverty of theory in corporate crime research. Advances in criminological theory, 1, 31-55.

5. Braithwaite, J., \& Fisse, B. (1990). On the plausibility of corporate crime theory. Advances in criminological theory, 2, 15-38.

6. Bucy, P. H. (1990). Corporate Ethos: A Standard for Imposing Corporate Criminal Liability. Minnesota Law Review, 75, 1095.

7. Jörg, N. (1997) The promise and Limitations of Corporate Criminal Liability. In Debating Corporate Crime, 99-116. Cincinnati: ACJS/Andersson. 
8. Blau, P. M. (1977). A Macrosociological Theory of Social Structure. American Journal of Sociology, 83(1), 26-54.

9. French, P. A. (1984). Corporate and collective responsibility. New York: Columbia University Press.

10. DeKeseredy, W. S., \& Goff, C. (1992). Corporate violence against canadian women: Assessing leftrealist research and policy. The Journal of Human Justice, 4(1), 55-70. https://doi.org/10.1007 /BF02619282.

11. Slapper, G., \& Tombs, S. (1999). Corporate Crime. London: Longman Group United Kingdom.

12. Geis, G. (1995). A Review, Rebuttal, and Reconciliation of Cressey and Braithwaite and Fisse on Criminological Theory and Corporate Crime. In The Legacy of Anomie Theory (pp. 399-428).

13. Aguilera, R. V., \& Vadera, A. K. (2007). The Dark Side of Authority: Antecedents, Mechanisms, and Outcomes of Organizational Corruption. Journal of Business Ethics, 77(4), 431-449. https://doi. org/10.1007/s10551-007-9358-8.

14. Harding, C. (2004). Forging the European Cartel Offence: The Supranational Regulation of Business Conspiracy. European Journal of Crime, Criminal Law and Criminal Justice, 12(4), 275-300. https://doi.org/10.1163/1571817042523121.

15. Green, G. S., \& Shou, H. (2015). Operationalizing organizational violence. In The Routledge international handbook of the crimes of the powerful (pp. 50-61). London: Routledge.

16. Simpson, S. S., \& Koper, C. S. (1992). Deterring Corporate Crime*. Criminology, 30(3), 347-376. https://doi.org/10.1111/j.1745-9125.1992.tb01108.x.

17. Shover, N., \& Bryant, K. M. (1993). Theoretical explanations of corporate crime. Understanding corporate criminality, 3, 141-176.

18. Gunningham, N. A., Thornton, D., \& Kagan, R. A. (2005). Motivating Management: Corporate Compliance in Environmental Protection*. Law \& Policy, 27(2), 289-316. https://doi.org/10.1111 /j.1467-9930.2005.00201.x.

19. Paternoster, R., \& Simpson, S. (1996). Sanction threats and appeals to morality: Testing a rational choice model of corporate crime. Law \& Society Review, 30(3), 549-583.

20. Monahan, S. C., \& Quinn, B. A. (2006). Beyond "bad apples" and "weak leaders" Toward a neoinstitutional explanation of organizational deviance. Theoretical Criminology, 10(3), 361-385. doi: https://doi.org/10.1177/1362480606065911

21. Ermann, M. D., \& Rabe, G. A. (1997). Organizational processes (not rational choices) produce most corporate crimes. In Debating corporate crime (pp. 53-67). Cincinnati: ACJS/Andersson.

22. Yeager, P. C. (1995). Management, morality and law: Organizational forms and ethical deliberations. In Corporate crime: Contemporary debates (pp. 147-167). Toronto: University of Toronto Press.

23. Punch, M. (2008). The organization did it: Individuals, corporations and crime. Corporate and whitecollar crime (pp. 102-121). London: Sage.

24. Shover, N., \& Hochstetler, A. (2006). Choosing white-collar crime. Cambridge: Cambridge Univ Pr.

25. Shover, N., Hochstetler, A., \& Alalehto, T. (2012). Choosing White-Collar Crime. In F. T. Cullen \& P. Wilcox (Red.), The Oxford Handbook of Criminological Theory. Oxford University Press: Oxford.

26. Hofstede, G., Hofstede, G. J., \& Minkov, M. (1997). Cultures and organizations. New York: McGraw Hill.

27. Pinto, J., Leana, C. R., \& Pil, F. K. (2008). Corrupt Organizations or Organizations of Corrupt Individuals? Two Types of Organization-Level Corruption. Academy of Management Review, 33(3), 685-709. https://doi.org/10.5465/AMR.2008.32465726.

28. Simon, H. A. (1971). Administrativt beteende: En studie av beslutsprocessen $i$ administrativa organisationer. Prisma: Stockholm.

29. Dalton, D. R., \& Kesner, I. F. (1988). On the dynamics of corporate size and illegal activity: An empirical assessment. Journal of Business Ethics, 7(11), 861-870. https://doi.org/10.1007/BF00383049.

30. Vaughan, D. (1998). Rational Choice, Situated Action, and the Social Control of Organizations. Law \& Society Review, 32(1), 23-61. https://doi.org/10.2307/827748.

31. Tännsjö, T. (2007). The Myth of Innocence: On Collective Responsibility and Collective Punishment. Philosophical Papers, 36(2), 295-314. https://doi.org/10.1080/05568640709485203.

32. Cullen, F. T., Cavender, G., Maakestad, W. J., \& Benson, M. L. (2014). Corporate Crime Under Attack: The Fight to Criminalize Business Violence. Abingdon: Routledge.

33. Vaughan, D. (1996). The Challenger launch decision: risky technology, culture, and deviance at NASA. Chicago: University of Chicago Press.

34. Ermann, M. D., \& Lundman, R. J. (2002). Corporate and Governmental Deviance: Origins, Patterns, and Reactions. Oxford University Press. Hämtad från. http://psycnet.apa.org/psycinfo/2004-14247-001

35. Geis, G. (2006). White-Collar and Corporate Crime (1:a uppl.). Prentice Hall: Upper Saddle River.

36. Parker, J. S. (1997). The Blunt Instrument. Debating Corporate Crime, 71, 76-77. 
37. Mueller, G. O. W. (1957). Mens Rea and the Corporations - A Study of the Model Penal Code Position on Corporate Criminal Liability. University of Pittsburgh Law Review, 19, 21.

38. Belbot, B. (1993). Corporate criminal liability. In Understanding corporate criminality (pp. 211-234). New York: Garland Publishing Inc.

39. Fisse, B., \& Braithwaite, J. (1983). The Impact of Publicity on Corporate Offenders. Albany: SUNY Press.

40. Simpson, S. S., Gibbs, C., Rorie, M., \& Slocum, L. A. (2013). Empirical Assessment of Corporate Environmental Crime-Control Strategies, An. Journal of Criminal Law and Criminology, 103, 231.

41. Alalehto TS (2007) Suspected irregularities in stock-exchange-listed companies: What are the effects of negative publicity? Monatsschrift für Kriminologie und Strafrechtsreform, hefte 2(3), 191-206.

42. Baucus, M. S., \& Near, J. P. (1991). Can Illegal Corporate Behavior Be Predicted? An Event History Analysis. The Academy of Management Journal, 34(1), 9-36. https://doi.org/10.2307/256300.

43. Coffee Jr., J. C. (1981). "No Soul to Damn: No Body to Kick": An Unscandalized Inquiry into the Problem of Corporate Punishment. Michigan Law Review, 79(3), 386-459. https://doi.org/10.2307 /1288201.

44. Craig Smith, N., Simpson, S. S., \& Huang, C.-Y. (2007). Why Managers Fail to do the Right Thing: An Empirical Study of Unethical and Illegal Conduct. Business Ethics Quarterly, 17(04), 633-667. https://doi.org/10.1017/S1052150X00002633.

45. Braithwaite, J., \& Makkai, T. (1991). Testing an Expected Utility Model of Corporate Deterrence. Law \& Society Review, 25(1), 7-40. https://doi.org/10.2307/3053888.

46. Giddens, A. (1984). The Constitution of Society: Outline of the Theory of Structuration. Berkeley: University of California Press.

47. Barnes, J. (1982). Medicine, experience and logic. Hämtad från. http://philpapers.org/rec/BARMEA-3

48. Tersman, F. (2001). Fem filosofiska frågor. Stocholm: Wahlström \& Widstrand.

49. Williamson, T. (2002). Vagueness. Abingdon: Routledge. 